\title{
The Effects of Rosmarinic Acid on Expression of Akt Genes in the Hippocampus of Diabetic Rats and DNA Glycation Inhibition.
}

\author{
Ameer Alrubaye \\ University of Isfahan \\ Majid Motovali-Bashi ( $\sim$ mbashi@sci.ui.ac.ir) \\ University of Isfahan \\ Mehran Miroliaei \\ University of Isfahan
}

\section{Research Article}

Keywords: Diabetes, DNA glycation, Akt genes, Rosmarinic acid, Hippocampus

Posted Date: July 20th, 2021

DOI: https://doi.org/10.21203/rs.3.rs-701800/v1

License: (c) (i) This work is licensed under a Creative Commons Attribution 4.0 International License.

Read Full License 


\section{Abstract}

Non-enzymatic glycation of DNA and the associated effects are among pathogenic factors in diabetes mellitus. Natural polyphenols have anti-diabetic activity. Herein, the protective role of one of the phytochemicals, rosmarinic acid (RA), was evaluated in glycation (with fructose) of human DNA and expression of Akt genes in the hippocampus of diabetic rats. In-vitro studies using fluorescence, agarose gel electrophoresis, fluorescence microscopy, and thermal denaturation analyses revealed that glycation causes DNA damage and that RA inhibits it. In-vivo studies were performed by induction of diabetes in rats using streptozotocin. The diabetic rats were given RA daily through gavage feeding. The expression of Akt genes (inhibitors of apoptosis) in the hippocampus was evaluated using RT-qPCR. In diabetic rats, Akt1 and Akt3 were significantly down-regulated compared to the control group. Treating the diabetic rats with RA returned the expression of Akt1 and Akt3 relatively to the normal condition. Past studies have shown that diabetes induces apoptosis in the hippocampal neurons. Given that glycation changes the genes expression and causes cell death, apoptosis of the hippocampal neurons can be due to the glycation of DNA. The results also suggest that RA has reliable potency against the gross modification of DNA under hyperglycemic conditions.

\section{Introduction}

Spontaneous glycation is a non-enzymatic process that occurs naturally under physiological conditions, but it is greatly intensified under hyperglycemic conditions and can be fatal. Glycation causes significant structural and conformational changes in biomolecules, which complicates degenerative diseases, including diabetes ${ }^{1}$. Non-enzymatic glycation proceeds in a step-wise manner and involves Schiff's base formation and Amadori rearrangements, resulting in the formation of Advanced Glycation End-products $(A G E s)^{2}$. Genetic materials, including DNA, are the biomolecules involved in such a harmful process ${ }^{3}$. Amino groups in nucleic acids can serve as a substrate for the non-enzymatic addition of reducing sugars, leading to some gross alteration in the DNA structure. The source of such non-enzymatic reactions is endogenous sugars, which can induce extensive damage to DNA, leading to much of the cellular mutations ${ }^{4}$. The force imposed by these processes might direct be related to the striking degree of deletions, duplications, insertions, or inter-strand cross-linking ${ }^{2}$.

DNA glycation and its consequences are more severe in diseases concerned with glycation factors aggregation, such as diabetes ${ }^{5}$. In diabetic conditions, fructose concentration increases by the polyol pathway in the independent tissues of insulin such as neural tissue ${ }^{6-8}$. Several studies have shown that experimental diabetes induces apoptosis in the hippocampal neurons ${ }^{9-12}$. The hippocampus is one of the sensitive regions of the brain against metabolic disorders such as diabetes ${ }^{13}$. The serine/threonine kinase Akt, known as protein kinase B (PKB), is a vital part of signal transduction in all eukaryotic cells and as one of the most important protein kinases, it plays a role in inducing cell division and preventing apoptosis $^{14}$. There are three AKT isoforms conserved in the mammalian genome: AKT1 (PKBa), AKT2 $(\mathrm{PKB} \beta)$, and AKT3 (PKBY). 
Given DNA glycation with different reducing sugars and the possible association of this event with diabetes, the search for tarping agents with the capability of targeting any step of the glycation pathway has always been a health concern. Inhibition of glycation, both in vivo and in food, is vital for promoting human health, especially for the control of diabetes ${ }^{15}$. To this end, bioactive phenols hold a remarkable potential to overcome the toxic effects of sugars ${ }^{16}$. Glycation-induced oxidative stress serves as the key pathogenetic stimulus for oxidative DNA damage, giving rise to characteristic nucleotide adducts ${ }^{17,18}$. Naturally occurring phytochemicals seem to be a helpful strategy to fight such a pernicious process. To find the extent to which the glycation process of DNA can be relieved, the impact of naturally occurring polyphenol, Rosmarinic acid (RA) with documented antioxidant, anti-inflammatory, antibacterial, and anti-

apoptotic activities ${ }^{19,20}$, was explored in the fructose-DNA model. This study aimed to evaluate the extent of fructose-mediated AGEs damage to DNA and its inhibition by the interference of RA, as well as evaluation of Akt genes expression in the hippocampus of diabetic rats treated with RA. Finally, we tried to explore the probable relationship between apoptosis of hippocampal neurons in diabetic conditions and DNA glycation.

\section{Results}

\section{Glycation and UV-vis spectroscopic characterization of DNA}

The absorption spectroscopic analysis of the fructose-modified DNA showed a broad absorption band centered at $260 \mathrm{~nm}$ with marked hyperchromicity after 15 days of incubation; this was comparable to the native form (Fig. 1). Upon glycation, the trend of kinetic changes at $260 \mathrm{~nm}$ kept on rising within 5, 10, and 15 days of incubation in the PBS (pH 7.4). Compared to the $260 \mathrm{~nm}$ peak of the native DNA, the hyperchromicities shown by 15 days was $29.11 \%$. Furthermore, the ratio of the intensities at $260: 280 \mathrm{~nm}$ (A260/A280) was decreased for DNA in the presence of fructose (Table 2).

\section{Agarose gel electrophoresis}

Agarose gel electrophoresis was used to determine the fate of DNA during fructation. Figure 2 demonstrates the electrophoretic analysis of the DNA incubated with fructose when RA was present. The difference in the band pattern and intensity was exceptionally informative. Electrophoretic migration of the native DNA reflected the pattern of the typical genomic DNA which was comparable to the migration pattern of the ligand-treated and modified DNA (Fig. 2). DNA sample not exposed to fructose migrated as a sharp single band initially with the appearance of an additional minor band, whereas the disappearance of the initial band was evident for the fructose-modified DNA (lane 1-3) even after 5 days of exposure. No remarkable changes were observed at the band intensities of the treated samples with RA (lane 7-9); meanwhile, for the samples exposed to fructose at a longer duration (10-and 15-days), their protective effect was substantial against lesions in DNA. The obtained results were comparable for the control samples (lane 4-6) with glycated (lane 1-3).

\section{Fluorescence studies}


Glycation causes AGEs to form in DNA along with additional fluorescent adducts that establish disrupt human genes ${ }^{21}$. DNA-AGEs were measured by fluorescence intensity at the excitation/emission wavelength of $370 / 440 \mathrm{~nm}$. The results obtained by fluorogenic AGEs experiments showed a great extent of alteration in the DNA structure after adding fructose (Fig.3 \& Table 2). It is worth noting that an interesting phenomenon occurred; about $43 \%$ of fluorescence intensity was diminished in the treatment with RA $(25 \mu \mathrm{M})$ (Fig.3).

\section{Fluorescence microscopy}

To further explore the binding nature of fructose with DNA and evaluate the RA influence, a visual inspection experiment was applied via fluorescence microscopy. As could be seen from the images of figure 4, after 15 days of incubation, amorphous-like aggregates were detected in the samples containing DNA-fructose (Fig. 4B), which was comparable to the control (Fig. 4A). Interestingly, after 15 days of incubation, these insoluble aggregates were markedly diminished by the presence of RA (Fig. 4C).

\section{Zeta Potential measurements}

The zeta-potentials of DNA, Fructose-DNA, and the sample treated with RA were $-3.5 \mathrm{mV},-0.5 \mathrm{mV}$, and $-1.8 \mathrm{mV}$, respectively (Fig. $5 \&$ Table 2). The results of the particle size distribution of RA complexes were still in the nano-size region.

\section{Thermal denaturation}

Thermal denaturation analysis was performed to address the impact of glycation. Based on thermal denaturation analysis, the melting temperature $(\mathrm{Tm})$ for the native, glycated, and RA treated DNA was 82 ${ }^{\circ} \mathrm{C}, 75^{\circ} \mathrm{C}$, and $79.3^{\circ} \mathrm{C}$, respectively (Table 2). Therefore, a decrease was observed in the Tm of the modified DNA.

\section{downregulation of $A k t 1$ and $A k t 3$ in the diabetic rat hippocampus}

$A k t 1$ and $A k t 3$ expression in diabetic rats showed a significant downregulation of $47 \%(P=0.0404)$ and $67 \%(P=0.0407)$, respectively, when compared with the control group (Figure 6A \& $C)$. Treating the diabetic rats with RA returned the expression of $A k t 1$ and $A k t 3$ relatively to the normal condition with $\mathrm{P}=$ 0.0231 and $\mathrm{P}=0.0236$, respectively (Figure $6 \mathrm{~A} \& \mathrm{C}$ ). The expression of the Akt2 was not significantly different among the three groups (Figure 6B).

\section{Discussion}

\section{Fructose as an important glycating agent}

In hyperglycemia and diabetic conditions, glucose concentration increases in the insulin-independent tissues such as neural tissue, glomeruli, lens, and erythrocytes. Accordingly, the polyol pathway can be activated and sorbitol is converted to fructose by sorbitol dehydrogenase ${ }^{6-8}$. The high reactivity of 
fructose, either directly or through its metabolites, may contribute to the formation of intracellular glycation products and vascular complications ${ }^{22}$. Interestingly, fructose's contribution to the onset of these deleterious reactions is 5-8 times higher than that of glucose ${ }^{23,24}$. Briefly, first, fructose has more reactivity than other sugars. Second, in tissues where the sorbitol pathway is active, glucose is converted to fructose. Third, in diabetic conditions, the amount of fructose in the eye lens may increase by 23 times ${ }^{25}$, making glycation a more likely event in the body. Therefore, in the present study, fructose was used as a glycating agent for these reasons.

\section{DNA glycation and inhibition by rosmarinic acid}

To determine the structural alteration of DNA during the reaction with fructose, UV spectroscopy and fluorescence study were employed. Ultraviolet spectroscopy is often used to determine the conformational changes of chromophores occurring in $\mathrm{DNA}^{26-28} .5,10$, and 15 days after glycation, the trend of the kinetic changes at $260 \mathrm{~nm}$ continued to increase. It could be concluded that fructose's modification of nitrogenous bases caused single-strand breakage, which resulted in the destruction of chromophore classes. As a result, the hypochromic phenomenon may be caused by dispersion force interactions between stacked chromophores, which could be explained in terms of extensive strand scission and intensity exchange between different transitions. Moreover, some slight red shifts at the peaks may result from the denaturation-dependent head-to-tail arrangement of the transition dipoles (Fig. 1). According to Table 2, which represents the difference in the ratio intensities of $A 260 / A 280$ for the native and glycated DNA, it could be seen how fructation caused marked changes in the structure of the DNA generating light-absorbing molecules.

In the agarose gel electrophoresis study, alteration in the migration profile of fructose-DNA might originate from the significant damage in the amino groups of nucleotides at the advanced glycation stages (15 days incubation), causing further rearrangement and destabilizing the phosphodiester backbone. Modification of DNA by fructose gives rise to breaking single strands and generating nucleotide adducts, due to increased oxidative stress ${ }^{21,29}$. Moreover, the formation of superoxide radicals is involved in the Maillard reaction of DNA with fructose and other sugars ${ }^{30}$. The significant decrease in the single strand breakage for the RA treated samples could be attributed to its established antioxidant activity ${ }^{19}$. Reactive oxygen species (ROS) are a potent mediator causing cellular stress originating from sugars auto-oxidation ${ }^{31,32}$.

Generation of fluorogenic AGEs in the glycated-DNA samples was probed at the excitation/emission wavelength of $370 / 440 \mathrm{~nm}$. Glycation of DNA by fructose generated fluorescent DNA_AGEs which could be characterized by the emission maxima of $440 \mathrm{~nm}$. This is a typical event of DNA-AGEs that has been detected in vitro in the process of glycation ${ }^{33}$. This finding is also consistent with another study, suggesting that AGEs could be formed as the end-product of DNA molecules, resulting in the singlestrand breakage ${ }^{30}$. The quenching effect of RA, as seen in figure 3 and table 2 , offers a clue for the reduction of advanced glycation end products during glycation. It suggested that the fructation of DNA 
resulted in the formation of nucleotide AGEs which could be associated with the increase in the mutation frequency and cytotoxicity ${ }^{34}$.

The results of the fluorescence microscope also confirmed those of the previous experiments. In the samples containing DNA-fructose, amorphous-like aggregates were observed (Fig. 4B); The presence of RA markedly diminished these insoluble aggregates (Fig. 4C) However, the reduction of the whole glycation-linked aggregation process by RA might originate from its preserving effect on the global fold of the DNA molecule. The occurrence of reactive Maillard intermediates with DNA may account for the strand scission and increased inter-strand crosslinking, culminating into adducts capable of forming yellow-brown fluorescent compounds ${ }^{35,36}$.

According to the zeta potential results, the particle sizes of the Fructose-DNA, RA-complex were comparable to that of the native DNA (Fig 5). It is obvious that in the DNA-fructose system in which RA was present, the change in particle size caused by the addition of fructose was much smaller than that of the modified DNA (Fig. 5 \& Table 2). Through these experiments, we found that the interaction of RA made the zeta-potential smaller than that in the fructose-DNA complex and the corresponding particle size obeyed the same trend.

From table 2, the decrease in the Tm of the modified DNA could be ascribed to the generation of singlestrand breaks and/or the altered hydrogen bonding between base pairs. The results were in the same trends of fluorescence intensity values (Table 2) obtained by AGE-specific fluorescence ( $\lambda$ ex $370 \mathrm{~nm}, \lambda$ em $440 \mathrm{~nm}$ ), thus largely representing the structure of the DNA change after adding fructose and protecting markedly by the applied RA.

Overall, our findings revealed that the fructation of DNA led to the formation of nucleotide adducts with increased oxidative stress. Thus, RA holds a considerable intervention potential with the underlying mechanism of fructose-mediated DNA-AGE formation. The inhibitory action of RA is partially due to its antioxidant potential and ROS scavenging activity; it could also be attributed to stacking with glycogenic nucleotides which direct the ligands to the glycogenic core, thereby counteracting the effect of the formed inter-strand cross-link in the duplex DNA. Since the mechanisms underlying the formation of advanced glycated-DNA may elevate the risk of cancer by enhancing the risk of mutagenesis, our results might help to design nutraceutical-based small molecules useful for decreasing the risk of mutation frequency and other DNA lesions leading to cytotoxicity.

\section{Diabetes, apoptosis in hippocampal neurons}

The previous studies provide evidence that both types of diabetes are associated with functional and structural disorders in the brain ${ }^{37-39}$. One of the most critical disorders is apoptosis in hippocampal neurons $^{9-12}$. Significant down-regulation expression of $A k t 1$ and $A k t 3$ (apoptosis inhibitor genes) in the current study also suggested the occurrence of apoptosis in the hippocampal neurons of STZ-induced diabetic rats. 


\section{Akt genes with a distinct hippocampal expression}

In the hippocampus, each $A k t$ isoform has a distinct expression pattern: $A k t 1$ and $A k t 3$ are predominantly expressed in neurons, while $A k t 2$ is primarily expressed in astrocytes and glia ${ }^{40}$. Akt2 deficiency is associated with insulin resistance, causing a diabetic syndrome with elevated plasma glucose levels; this suggests that $A k t 2$ is involved in the insulin signal ${ }^{41}$. These results, therefore, suggest that the reason for no significant difference in the mRNA level of $A k t 2$ in the present study could be the close relationship between the expression of this gene and insulin and blood sugar levels, as well as insulin signal. It is thought-provoking that astrocytes, unlike neurons, are insulin-dependent, and the present study emphasizes the possibility of DNA glycation in non-insulin-dependent cells.

\section{A link between apoptosis of hippocampal neurons in diabetic conditions and DNA fructation}

Diabetes is associated with oxidative stress due to the increased free radical formation and the decreased activity of the antioxidant defense systems ${ }^{42}$. Hyperglycemia causes increased formation of Reactive Oxygen Species (ROS) through several pathways, including the polyol pathway and glycation ${ }^{30,43}$. Glycation and AGEs change the expression of genes ${ }^{44,45}$, as well as cause cell death ${ }^{46}$.

According to these results, as well as those in previous sections, apoptosis in hippocampal neurons may be related to DNA damage induced by the polyol pathway's increased fructose concentration; In other words, apoptosis of the hippocampal neurons can be due to the glycation of DNA. Significant relative return of $A k t 1$ and $A k t 3$ expression to the normal state, based on the treatment of STZ-induced diabetic rats with RA as a natural phenol with the ability to inhibit glycation, confirms the possibility of apoptosis due to the DNA glycation.

\section{Conclusion}

The findings of this research, confirm the anti-glycation properties of rosmarinic acid and point to it as a potential biophenol that can effectively minimize diabetes complications. According to the current study, hippocampal nerve cell apoptosis in diabetics may be due to DNA glycation. Therefore, further study into the likelihood of DNA glycation inside diabetic hippocampal neurons and other insulin-independent tissues is suggested to validate this phenomenon.

\section{Materials And Methods}

All of the chemicals used in this study, whose manufacturer is not listed in the text, are from Sigma Chemical Company, USA.

\section{Isolation of Human DNA}

Blood was drawn from healthy individuals. Blood was collected according to the instructions of the Ministry of Health of the Islamic Republic of Iran (Ethical number: IR.UI.REC.1399.056). Genomic DNA was isolated by optimization of the Proteinase K-Buffer method ${ }^{47}$, using lysis buffer A ( $11 \%$ sucrose, $1 \%$ 
Triton X-100, 5 mM MgCl2, 10 mM Tris pH 8) and buffer B (10 mM sodium citrate, 1\% SDS, 10 mM Tris, 10 mM EDTA pH 8.0), from human blood.

\section{Preparation of glycated and treated DNA whit RA}

In vitro glycation of DNA was done and characterized, as previously described ${ }^{48}$. To summarize, DNA (20 $\mathrm{ng} / \mu$ l final concentration) from the blood of non-diabetic individuals was incubated with 25 mM fructose at $37^{\circ} \mathrm{C}$ for 5,10 , and 15 days in the presence or absence of RA ( $25 \mu \mathrm{M}$ final concentration) in phosphate buffer saline (PBS). This fructose concentration correlates to the minimum concentration needed for in vitro DNA glycation ${ }^{49}$. It has also been shown that $25 \mu \mathrm{M}$ rosmarinic acid reduces the glycosylation of human fibroblasts in vitro ${ }^{50} .0 .02 \%(\mathrm{w} / \mathrm{v})$ NaN3 was added to the solution and purified into a low proteinbinding filter (-GV $0.22 \mu \mathrm{m}$ filter unit, Millipore) to avoid bacterial contamination. Aliquots were taken from the DNA-fructose solution after each incubation period and extensively dialyzed against the sterile PBS at $4{ }^{\circ} \mathrm{C}$ to remove the free fructose molecules. Under the same conditions, pure DNA solution was used as the control sample.

\section{UV-Visible spectroscopy}

The UV-vis spectroscopy was used to confirm the structural changes induced in the human blood DNA. The ultraviolet absorption profile of the modified DNA (20 ng/ $\mu$ l final concentration), incubated with 25 $\mathrm{mM}$ fructose at $37^{\circ} \mathrm{C}$ for 5,10 and 15 days in the PBS, was recorded in the wavelength range of 200-400 $\mathrm{nm}$ on the UV-2100 spectrophotometer in a quartz cuvette with $1 \mathrm{~cm}$ path length ${ }^{27}$.

\section{Agarose gel electrophoresis}

To evaluate the effect of glycation (fructation) on DNA, $5 \mu$ of native, glycated, and treated DNA was mixed with $1 \mu$ l of the loading dye $6 \mathrm{X}$ buffer. The samples were loaded into the wells of $1.5 \%$ agarose gel and electrophoresed for $1.5 \mathrm{~h}$ at $100 \mathrm{v}$. The gels were stained with ethidium bromide $(0.5 \mathrm{mg} / \mathrm{ml})$, viewed by illumination under UV light, and photographed.

\section{Fluorescence studies}

Fluorescence measurements were made on a Cary-Eclipse spectrophotometer (Varian model, Australia). Sample mixtures showing absorbance changes were subjected to the excitation wavelength of $370 \mathrm{~nm}$ and the emission wavelengths were recorded at the range of 380-500 nm. Fluorescence spectra of the modified nucleotides and DNA were determined by the subtraction of the background fluorescence of fructose and its possible degradation product during prolonged incubation.

\section{Fluorescence microscopy}

Fluorescence microscopic measurements were performed using ThT dye ( $\lambda$ ex $440 \mathrm{~nm}, \lambda \mathrm{em} 480 \mathrm{~nm}$ ) to visualize the morphological structure of the inter-strand cross-links formed in the duplex DNA molecules and the inhibitory activity of biophenol ${ }^{51}$. ThT $(32 \mu \mathrm{M})$ was mixed with native (at $\left.25^{\circ} \mathrm{C}\right)$ and glycated 
DNA samples in the absence and presence of biophenols. After 60 min incubation at room temperature, $15 \mu \mathrm{l}$ of each sample was transferred on cleaned glass slides to be analyzed under fluorescence microscopy. The images were obtained with an Olympus IX71 fluorescence microscope equipped with a digital CCD camera at 20 and 40 objective magnifications.

\section{Zeta Potential measurements}

Zeta potential evaluation was done according to the method developed by Chetty and Singh ${ }^{26}$. To describe briefly, the zeta potential and average particle sizes of DNA, DNA/Fructose, and biophenolDNA/Fructose were determined by using ZetasizerNano-ZS90 (Malvern Instruments, Ltd.UK). The sample solution of DNA/Fructose $(1 \mathrm{mg} / \mathrm{mL})$ and biphenol-DNA/Fructose was placed in the test vessel; the average of three repeats of the measurements was reported. The molar ratio of biophenol to DNA/Fructose in the mixed system was 1:1.

\section{Thermal denaturation (Tm Measurement)}

A temperature scan of $30-95^{\circ} \mathrm{C}$ at an increment of $1{ }^{\circ} \mathrm{C} / \mathrm{min}$ was performed with a Shimadzu UV-240 spectrophotometer fitted with a temperature programmer and controller assembly; The thermal denaturation of native, glycated, and RA DNA samples was evaluated under similar conditions. Absorbance change $(260 \mathrm{~nm})$ and the melting temperature $(\mathrm{Tm})$ of the samples were reported ${ }^{52}$.

\section{Experimental animals and samples collection}

Male rats (Rattus Norvegicus) with an average weight of 200-220 g were purchased from the Faculty of Pharmacy, University of Isfahan. In the animal room of the Faculty of Science, University of Isfahan., Iran, the animals were housed in a 12-h alternating light-dark cycle at a temperature of $21 \pm 2{ }^{\circ} \mathrm{C}$. All experiments were approved by the Ethics Committee of the University of Isfahan, Iran, (Ethical number: IR.UI.REC.1399.056); they were conducted according to the guide for the Internationally Accepted Principles for Animal Use and Care ${ }^{53}$. The rats were divided into three groups $(n=8)$ : (i) Control group, (ii) diabetic group, and (iii) diabetic group treated with RA. Sixteen animals were fasted for $24 \mathrm{~h}$, and diabetes was induced using a single intraperitoneal injection (i.p.) of Streptozotocin (STZ) $(45 \mathrm{mg} / \mathrm{kg}$, freshly dissolved in $0.1 \mathrm{M}$ citrate buffer, $\mathrm{pH}$ 4). Three days later, fasting blood glucose levels were determined using tail blood. Only rats were considered diabetic if basal blood glucose levels exceeded $250 \mathrm{mg} / \mathrm{dl}$. After confirmation of diabetes, eight rats in the diabetic group received $30 \mathrm{mg} / \mathrm{kg} \mathrm{RA}$ (mixed in deionized water), once daily by oral gavage for 8 weeks. This concentration of RA shows anti-oxidant and antiglycate effects in diabetic rats by reducing the formation of advanced glycation end products ${ }^{54}$. Rats in the control groups were given an equal volume of water. The animals were anesthetized with a mixture of pentobarbital sodium and phenytoin sodium (Euthanasia III) at the end of week 8 . Rats were sacrificed when they failed to respond to a toe pinch. The hippocampus tissue samples were isolated and flash frozen in liquid nitrogen; they were preserved at $-80^{\circ} \mathrm{C}$ until further experiments.

\section{Total RNA extraction and reverse transcription.}


Total RNA was extracted from the hippocampus tissue samples using Trizol reagent, according to the manufacturer's instructions. The extracted RNA was dissolved in DEPC-treated water. Gel electrophoresis was used to check the quality of the isolated RNA; also, Nanodrop (Thermo fisher-Onec) was used to determine the RNA concentration. Reverse transcription was conducted on 1000 nanograms of the total RNA in a final volume of $20 \mu \mathrm{l}$. Under the conditions suggested by the supplier (Thermo Fisher), cDNA was synthesized using the random hexamer primers and MMLV-reverse transcriptase.

\section{Primer design for real-time PCR}

The primers were designed using Oligo 7 and Beacon Designer 8 software. For Akt1 (NM_033230.2), Akt2 (NM_017093.1), Akt3 (NM_031575.1), and Beta-actin (NM_031144.3), the specific primers should result in a 156, 127, 107, and 123 bps product, respectively. The primer sequences are listed in Table 1.

\section{Akt genes expression analysis by real-time PCR}

For the amplification of $A k t, 1 \mu \mathrm{l} \mathrm{cDNA}$ was added to the SYBRGreen Master Mix (Ampliqon) containing the specific primers. Real-time PCR was performed in a Bio-Rad thermocycler. The same total volume (12 $\mu \mathrm{l})$ and thermal settings were used for all genes: $5 \mathrm{~min}$ of pre-incubation at $95^{\circ} \mathrm{C}$ and this was followed by 40 cycles of $30 \mathrm{~s}$ at $95^{\circ} \mathrm{C}, 30 \mathrm{~s}$ at $58^{\circ} \mathrm{C}$, and $30 \mathrm{~s}$ at $72^{\circ} \mathrm{C}$. The melting curve plot was drawn between 55 and $95^{\circ} \mathrm{C}$. Triplicates of each sample were run.

\section{Statistical analysis}

All data were presented as means \pm standard deviation (SD). Statistical analysis was performed by oneway ANOVA, using GraphPad Prism software, version 7. A Duncan's post-hoc comparison was then made

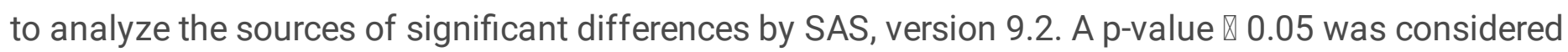
statistically significant.

\section{Declarations}

Ethical approval: The study was approved by the Ethics Committee of Research, University of Isfahan, Iran (IR.UI.REC.1399.056). Blood collecting was performed in accordance with the seventh edition of the Helsinki declaration and the research protocol was first submitted to the Ethics Committee of Research, University of Isfahan. knowledgeable consent, including the aims, methods, and sources of funding, institutional affiliations of the researchers, the anticipated benefits, and post-study provisions, was obtained for each blood donor. It should be noted that the donors had no diabetes and were over 18 years of age.

Also, the present study was approved by the Institutional Animal Care and Use Ethics Committee of the University of Isfahan, Iran, (Ethical number: IR.UI.REC.1399.056) and carried out in compliance with the ARRIVE guidelines. The method of caring for mice as well as their anesthesia is described in the materials and methods section, experimental animals and, samples collection. 
Ameer Alrubaye: Worked out all of the experiments. Wrote the manuscript.

Majid Motovali-Bashi: Conceived and planned the Project. Edited and corrected the manuscript.

Mehran Miroliaei: Designed the Biochemistry part of the project.

\section{Conflict of Interests}

The author(s) declared no potential conflicts of interest with respect to the research, authorship, and/or publication of this article.

\section{Acknowledgments}

This study was carried out at University of Isfahan and was financially supported by the Graduate Studies Office. The authors are grateful to the Graduate Office of the University of Isfahan for their support. We would also like to thank Dr. S.J Moshtaghian for his precious help in the animal trials test.

\section{References}

1. Ahmed, N. Advanced glycation endproducts-role in pathology of diabetic complications. Diabetes research and clinical practice 67, 3-21, doi:https://doi.org/10.1016/j.diabres.2004.09.004 (2005).

2. Ottum, M. S. \& Mistry, A. M. Advanced glycation end-products: modifiable environmental factors profoundly mediate insulin resistance. Journal of clinical biochemistry and nutrition $\mathbf{5 7}, \mathbf{1 - 1 2}$, doi:https://doi.org/10.3164/jcbn.15-3. (2015).

3. Shahab, U. et al. Immunogenicity of DNA-advanced glycation end product fashioned through glyoxal and arginine in the presence of $\mathrm{Fe} 3+$ : its potential role in prompt recognition of diabetes mellitus auto-antibodies. Chemico-biological interactions 219, 229-240, doi:https://doi.org/10.1016/j.cbi.2014.06.012 (2014).

4. Thornalley, P. Protecting the genome: defence against nucleotide glycation and emerging role of glyoxalase I overexpression in multidrug resistance in cancer chemotherapy. Biochemical Society Transactions 31, 1372-1377, doi:https://doi.org/10.1042/bst0311372 (2003).

5. Thornalley, P. J., Langborg, A. \& Minhas, H. S. Formation of glyoxal, methylglyoxal and 3deoxyglucosone in the glycation of proteins by glucose. Biochemical Journal 344, 109-116 (1999).

6. Gabbay, K. H. The sorbitol pathway and the complications of diabetes. New England Journal of Medicine 288, 831-836, doi:https://doi.org/10.1056/NEJM197304192881609 (1973).

7. Gabbay, K. H. in Vascular and neurological changes in early diabetes 417-424 (Elsevier, 1973).

8. Gabbay, K. H., Merola, L. O. \& Field, R. A. Sorbitol pathway: presence in nerve and cord with substrate accumulation in diabetes. Science 151, 209-210, doi:https://doi.org/10.1126/science.151.3707.209 (1966). 
9. Yonguc, G. N. et al. Grape seed extract has superior beneficial effects than vitamin E on oxidative stress and apoptosis in the hippocampus of streptozotocin induced diabetic rats. Gene 555, 119-126, doi:https://doi.org/10.1016/j.gene.2014.10.052 (2015).

10. Sun, L.-J. et al. Fish oil modulates glycogen synthase kinase-3 signaling pathway in diabetesinduced hippocampal neurons apoptosis. Brain research 1574, 37-49, doi:https://doi.org/10.1016/j.brainres.2014.05.050 (2014).

11. Chen, Y. et al. Effects of naokang erhao decoction on cognitive ability and hippocampal apoptosisrelated proteins in diabetic rats. Zhongguo Zhong yao za zhi= Zhongguo zhongyao zazhi= China journal of Chinese materia medica 36, 1519-1523 (2011).

12. Zhang, T., Jia, W. \& Sun, X. 3-n-Butylphthalide (NBP) reduces apoptosis and enhances vascular endothelial growth factor (VEGF) up-regulation in diabetic rats. Neurological research 32, 390-396, doi:https://doi.org/10.1179/016164110X12670144526264 (2010).

13. Malekiyan, R., Abdanipour, A., Sohrabi, D. \& Jafari Anarkooli, I. Antioxidant and neuroprotective effects of lycopene and insulin in the hippocampus of streptozotocin-induced diabetic rats. Biomedical reports 10, 47-54, doi:https://doi.org/10.3892/br.2018.1171 (2019).

14. Manning, B. D. \& Toker, A. AKT/PKB signaling: navigating the network. Cell 169, 381-405, doi:https://doi.org/10.1016/j.cell.2017.04.001 (2017).

15. Delgado-Andrade, C. Carboxymethyl-lysine: thirty years of investigation in the field of AGE formation. Food \& function 7, 46-57, doi:https://doi.org/10.1039/C5F000918A (2016).

16. Yeh, W.-J., Hsia, S.-M., Lee, W.-H. \& Wu, C.-H. Polyphenols with antiglycation activity and mechanisms of action: A review of recent findings. Journal of food and drug analysis 25, 84-92, doi:https://doi.org/10.1016/j.jfda.2016.10.017 (2017).

17. Ahmad, S. et al. Glycoxidative damage to human DNA: Neo-antigenic epitopes on DNA molecule could be a possible reason for autoimmune response in type 1 diabetes. Glycobiology 24, 281-291, doi:https://doi.org/10.1093/glycob/cwt109 (2014).

18. Wani, A., Mushtaq, S. \& Ahsan, H. Characterization of human glycated DNA modified with peroxynitrite. Helix-The Scientific Explorer 2, 221-225 (2013).

19. Cao, H. et al. DFT study on the antioxidant activity of rosmarinic acid. Journal of Molecular Structure: THEOCHEM 719, 177-183, doi:https://doi.org/10.1016/j.theochem.2005.01.029 (2005).

20. Petersen, M. \& Simmonds, M. S. Rosmarinic acid. Phytochemistry 62, 121-125, doi:https://doi.org/10.1016/S0031-9422(02)00513-7 (2003).

21. Bucala, R., Lee, A. T., Rourke, L. \& Cerami, A. Transposition of an Alu-containing element induced by DNA-advanced glycosylation endproducts. Proceedings of the National Academy of Sciences $\mathbf{9 0 ,}$ 2666-2670, doi:https://doi.org/10.1073/pnas.90.7.2666 (1993).

22. Gugliucci, A. Formation of fructose-mediated advanced glycation end products and their roles in metabolic and inflammatory diseases. Advances in nutrition 8, 54-62, doi:https://doi.org/10.3945/an.116.013912 (2017). 
23. Kazemi, F., Divsalar, A., Saboury, A. A. \& Seyedarabi, A. Propolis nanoparticles prevent structural changes in human hemoglobin during glycation and fructation. Colloids and Surfaces $B$ : Biointerfaces 177, 188-195, doi:https://doi.org/10.1016/j.colsurfb.2019.01.046 (2019).

24. Iannuzzi, C., Irace, G. \& Sirangelo, I. Differential effects of glycation on protein aggregation and amyloid formation. Frontiers in molecular biosciences 1, 9, doi:https://doi.org/10.3389/fmolb.2014.00009 (2014).

25. Suarez, G., Rajaram, R., Oronsky, A. \& Gawinowicz, M. Nonenzymatic glycation of bovine serum albumin by fructose (fructation): comparison with the Maillard reaction initiated by glucose. Journal of Biological Chemistry 264, 3674-3679, doi:https://doi.org/10.1016/S0021-9258(19)84904-9 (1989).

26. Chetty, R. \& Singh, M. In-vitro interaction of cerium oxide nanoparticles with hemoglobin, insulin, and dsDNA at $310.15 \mathrm{~K}$ : Physicochemical, spectroscopic and in-silico study. International journal of biological macromolecules 156, 1022-1044, doi:https://doi.org/10.1016/j.ijbiomac.2020.03.067 (2020).

27. Shahab, U. et al. Acquired immunogenicity of human DNA damaged by N-hydroxy-N-acetyl-4aminobiphenyl. IUBMB life 64, 340-345, doi: https://doi.org/10.1002/iub.1008 (2012).

28. Basu, S. \& Dasgupta, N. Spectrophotometric investigation of DNA in the ultraviolet. Biochimica et Biophysica Acta (BBA)-Nucleic Acids and Protein Synthesis 145, 391-397, doi:https://doi.org/10.1016/0005-2787(69)90240-8 (1967).

29. Mistry, N. et al. Novel monoclonal antibody recognition of oxidative DNA damage adduct, deoxycytidine-glyoxal. Laboratory investigation 83, 241-250, doi:https://doi.org/10.1097/01.lab.0000053915.88556.ed (2003).

30. Morita, J. \& Kashimura, N. The Maillard reaction of DNA with D-fructose 6-phosphate. Agricultural and biological chemistry 55, 1359-1366, doi:https://doi.org/10.1080/00021369.1991.10870762 (1991).

31. Thornalley, P. J. Monosaccharide autoxidation in health and disease. Environmental Health Perspectives 64, 297-307, doi:https://doi.org/10.1289/ehp.8564297 (1985).

32. Nakayama, T., Kimura, T., Kodama, M. \& Nagata, C. Generation of hydrogen peroxide and superoxide anion from active metabolites of naphthylamines and aminoazo dyes: its possible role in carcinogenesis. Carcinogenesis 4, 765-769, doi:https://doi.org/10.1093/carcin/4.6.765 (1983).

33. Ahmad, S., Dixit, K., Shahab, U., Alam, K. \& Ali, A. Genotoxicity and immunogenicity of DNA-advanced glycation end products formed by methylglyoxal and lysine in presence of Cu2+. Biochemical and biophysical research communications 407, 568-574, doi:https://doi.org/10.1016/j.bbrc.2011.03.064 (2011).

34. Murata-Kamiya, N., Kamiya, H., Kaji, H. \& Kasai, H. Glyoxal, a major product of DNA oxidation, induces mutations at G: C sites on a shuttle vector plasmid replicated in mammalian cells. Nucleic acids research 25, 1897-1902, doi:https://doi.org/10.1093/nar/25.10.1897 (1997). 
35. Lapolla, A., Traldi, P. \& Fedele, D. Importance of measuring products of non-enzymatic glycation of proteins. Clinical biochemistry 38, 103-115, doi:https://doi.org/10.1016/j.clinbiochem.2004.09.007 (2005).

36. Bucala, R., Model, P. \& Cerami, A. Modification of DNA by reducing sugars: a possible mechanism for nucleic acid aging and age-related dysfunction in gene expression. Proceedings of the National Academy of Sciences 81, 105-109, doi:https://doi.org/10.1073/pnas.81.1.105 (1984).

37. Zhou, X. et al. Aggravated cognitive and brain functional impairment in mild cognitive impairment patients with type 2 diabetes: a resting-state functional MRI study. Journal of Alzheimer's Disease 41, 925-935, doi:https://doi.org/10.3233/JAD-132354. (2014).

38. Van Harten, B., Oosterman, J. M., van Loon, B.-J. P., Scheltens, P. \& Weinstein, H. C. Brain lesions on MRI in elderly patients with type 2 diabetes mellitus. European neurology $57,70-74$, doi:https://doi.org/10.1159/000098054 (2007).

39. Meece, J. Diabetes mellitus: Pathophysiology and complications. International journal of pharmaceutical compounding 7, 17 (2003).

40. Levenga, J. et al. AKT isoforms have distinct hippocampal expression and roles in synaptic plasticity. Elife 6, e30640, doi:https://doi.org/10.7554/eLife.30640. (2017).

41. Dummler, B. et al. Life with a single isoform of Akt: mice lacking Akt2 and Akt3 are viable but display impaired glucose homeostasis and growth deficiencies. Molecular and cellular biology 26, 80428051, doi:https://doi.org/10.1128/MCB.00722-06 (2006).

42. Martín-Gallán, P., Carrascosa, A., Gussinyé, M. \& Domínguez, C. Biomarkers of diabetes-associated oxidative stress and antioxidant status in young diabetic patients with or without subclinical complications. Free Radical Biology and Medicine 34, 1563-1574, doi:https://doi.org/10.1016/S0891-5849(03)00185-0 (2003).

43. Wolff, S. P., Jiang, Z. Y. \& Hunt, J. V. Protein glycation and oxidative stress in diabetes mellitus and ageing. Free Radical Biology and Medicine 10, 339-352, doi:https://doi.org/10.1016/08915849(91)90040-A (1991).

44. Sun, F., Suttapitugsakul, S., Xiao, H. \& Wu, R. Comprehensive Analysis of Protein Glycation Reveals Its Potential Impacts on Protein Degradation and Gene Expression in Human Cells. Journal of The American Society for Mass Spectrometry 30, 2480-2490, doi:https://doi.org/10.1007/s13361-01902197-4 (2019).

45. Molinari, J., Ruszova, E., Velebny, V. \& Robert, L. Effect of advanced glycation endproducts on gene expression profiles of human dermal fibroblasts. Biogerontology 9, 177-182, doi:https://doi.org/10.1007/s10522-008-9129-7 (2008).

46. Peterszegi, G., Molinari, J., Ravelojaona, V. \& Robert, L. Effect of advanced glycation end-products on cell proliferation and cell death. Pathologie Biologie 54, 396-404, doi:https://doi.org/10.1016/j.patbio.2006.07.003 (2006).

47. MWer, S., Dykes, D. \& Polesky, H. A simple salting out procedure for extracting DNA from human nucleated cells. Nucleic acids res 16, 1215, doi:https://doi.org/10.1093/nar/16.3.1215 (1988). 
48. Zhang, G., Zhou, Z., Xu, J., Liao, Y. \& Hu, X. Groove binding between ferulic acid and calf thymus DNA: spectroscopic methodology combined with chemometrics and molecular docking studies. Journal of Biomolecular Structure and Dynamics, doi:https://doi.org/10.1080/07391102.2019.1624194 (2019).

49. Mustafa, I., Ahmad, S., Dixit, K., Ahmad, J. \& Ali, A. Glycated human DNA is a preferred antigen for anti-DNA antibodies in diabetic patients. Diabetes research and clinical practice 95, 98-104, doi:https://doi.org/10.1016/j.diabres.2011.09.018 (2012).

50. Iwona, R. \& Katarzyna, S. Glycosylation of proteins of human skin fibroblasts is changed by rosmarinic acid. Naunyn-Schmiedeberg's archives of pharmacology 393, 419-427, doi:https://doi.org/10.1007/s00210-019-01732-0 (2020).

51. Kasai, H., Iwamoto-Tanaka, N. \& Fukada, S. DNA modifications by the mutagen glyoxal: adduction to G and C, deamination of C and GC and GA cross-linking. Carcinogenesis 19, 1459-1465, doi:https://doi.org/10.1093/carcin/19.8.1459 (1998).

52. Habib, S., Ali, A. \& Ali, R. Preferential recognition of peroxynitrite modified human DNA by circulating autoantibodies in cancer patients. Cellular immunology 254, 117-123, doi:https://doi.org/10.1016/j.cellimm.2008.08.002 (2009).

53. Zimmermann, M. Ethical guidelines for investigations of experimental pain in conscious animals. Pain 16, 109-110, doi:https://doi.org/10.1016/0304-3959(83)90201-4 (1983).

54. Ou, J., Huang, J., Zhao, D., Du, B. \& Wang, M. Protective effect of rosmarinic acid and carnosic acid against streptozotocin-induced oxidation, glycation, inflammation and microbiota imbalance in diabetic rats. Food \& function 9, 851-860, doi:https://doi.org/10.1039/C7F001508A (2018).

\section{Tables}

Table 1. Primer used for the real-time PCR.

\begin{tabular}{|ll|}
\hline Gene & Primer for real-time PCR \\
Akt1 & 5'-TCCCTTCCTTACAGCCCTCAAG-3'-sense \\
(NM_033230) & 5'-GACACAATCTCCGCACCGTAG -3'-antisense \\
Akt2 & 5'-TTCCTTACAGCCCTGAAGTATGCC-3'-sense \\
(NM_017093) & 5'-GTGCCCGATCCTCCGTGA-3'-antisense \\
Akt3 & 5'-GAACGACCAAAGCCAAATACA-3' -sense \\
(NM_031575) & 5'-TCTGTCCATTCTTCTCTTTCCT -3'-antisense \\
Beta-actin & 5'-CTCTATGCCAACACAGTG -3'-sense \\
(NM_031144) & 5'-AGGAGGAGCAATGATCTT -3'-antisense \\
\hline
\end{tabular}

Table 2. Characterization of the native DNA glycated and treated with RA under identical conditions. 


\begin{tabular}{|llll|}
\hline Parameter & Native DNA & DNA + Fructose & DNA + Fructose + RA \\
\hline Absorbance ratio (A260/A280) & 1.84 & 1.44 & - \\
\hline Hyperchromicity (\%) & - & 29.11 & - \\
\hline Fluorescence intensity & 25 & 110 & 67 \\
\hline Melting temperature (Tm), ${ }^{\circ} \mathrm{C}$ & 82 & 75 & 79.3 \\
\hline Zeta potential (Mean) (mV) & -3.5 & -0.5 & -1.8 \\
\hline
\end{tabular}

\section{Figures}

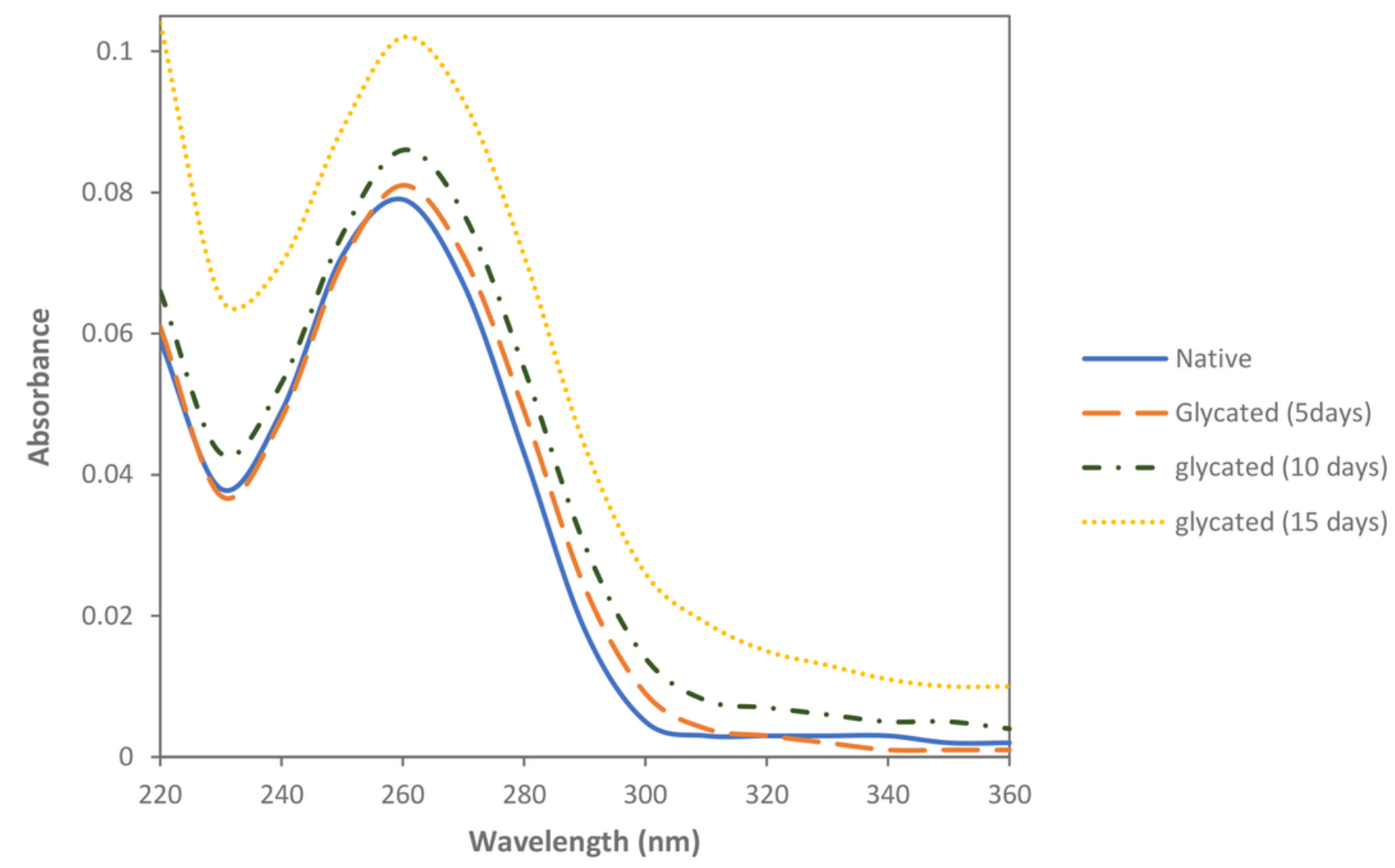

Figure 1

UV absorption of the Native DNA (-) and DNA incubated with fructose $25 \mathrm{mM}$, after $5(--), 10(--$.$) and 15$ days $(. .$.$) .$ 


\begin{tabular}{|ccc|ccc|ccc|}
\hline \multicolumn{3}{|c|}{ Glycated } & \multicolumn{3}{c|}{ Native } & \multicolumn{3}{c|}{ Treated with RA } \\
5 & 10 & 15 & 5 & 10 & 15 & 5 & 10 & 15 \\
days & days & days & days & days & days & days days days
\end{tabular}

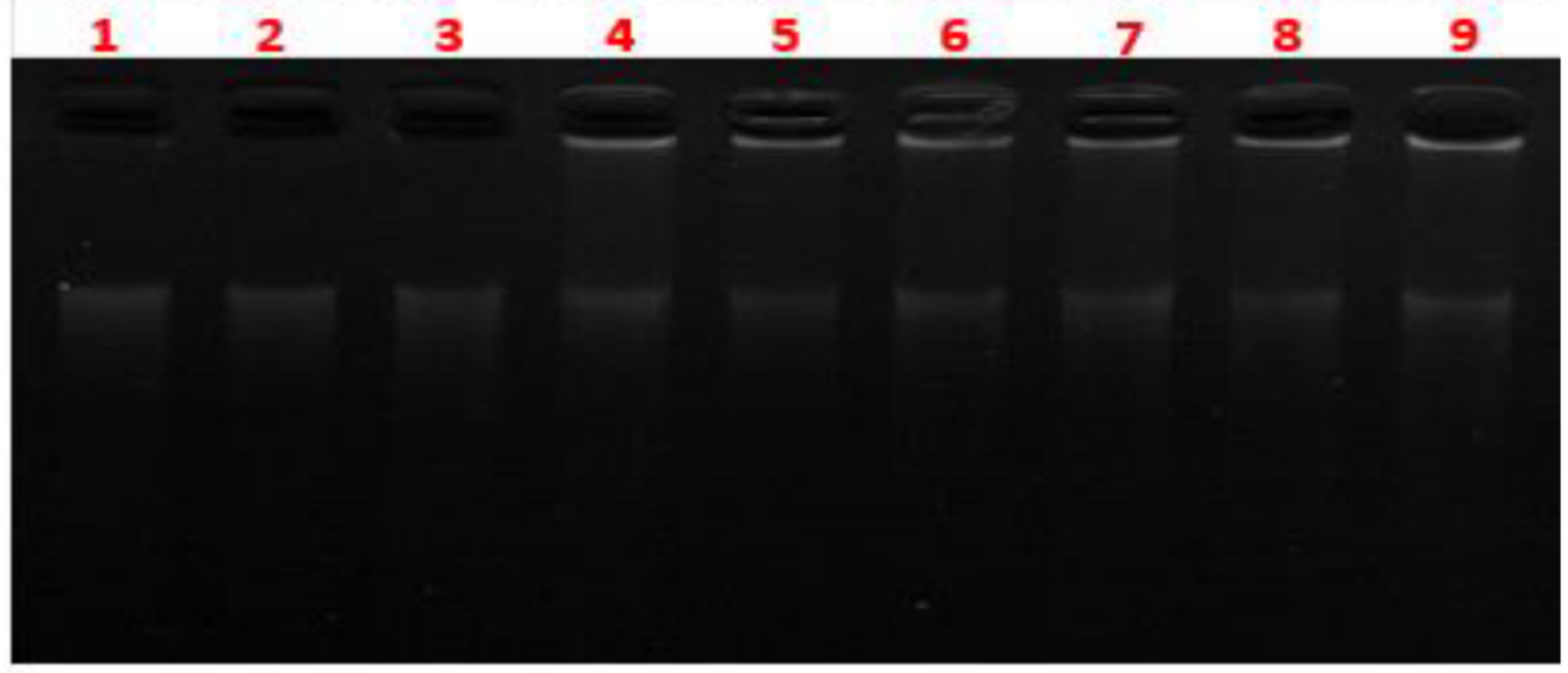

Figure 2

Agarose gel electrophoresis of the glycated DNA incubated with fructose for 5, 10, and 15 days (lane 1-3), the native DNA (lane 4-6), and DNA + Fructose after treating with RA for 5, 10, and 15 days (lane 7-9). Electrophoresis was carried out on the $1.5 \%$ agarose gel for $1.5 \mathrm{~h}$ at $100 \mathrm{v}$. 


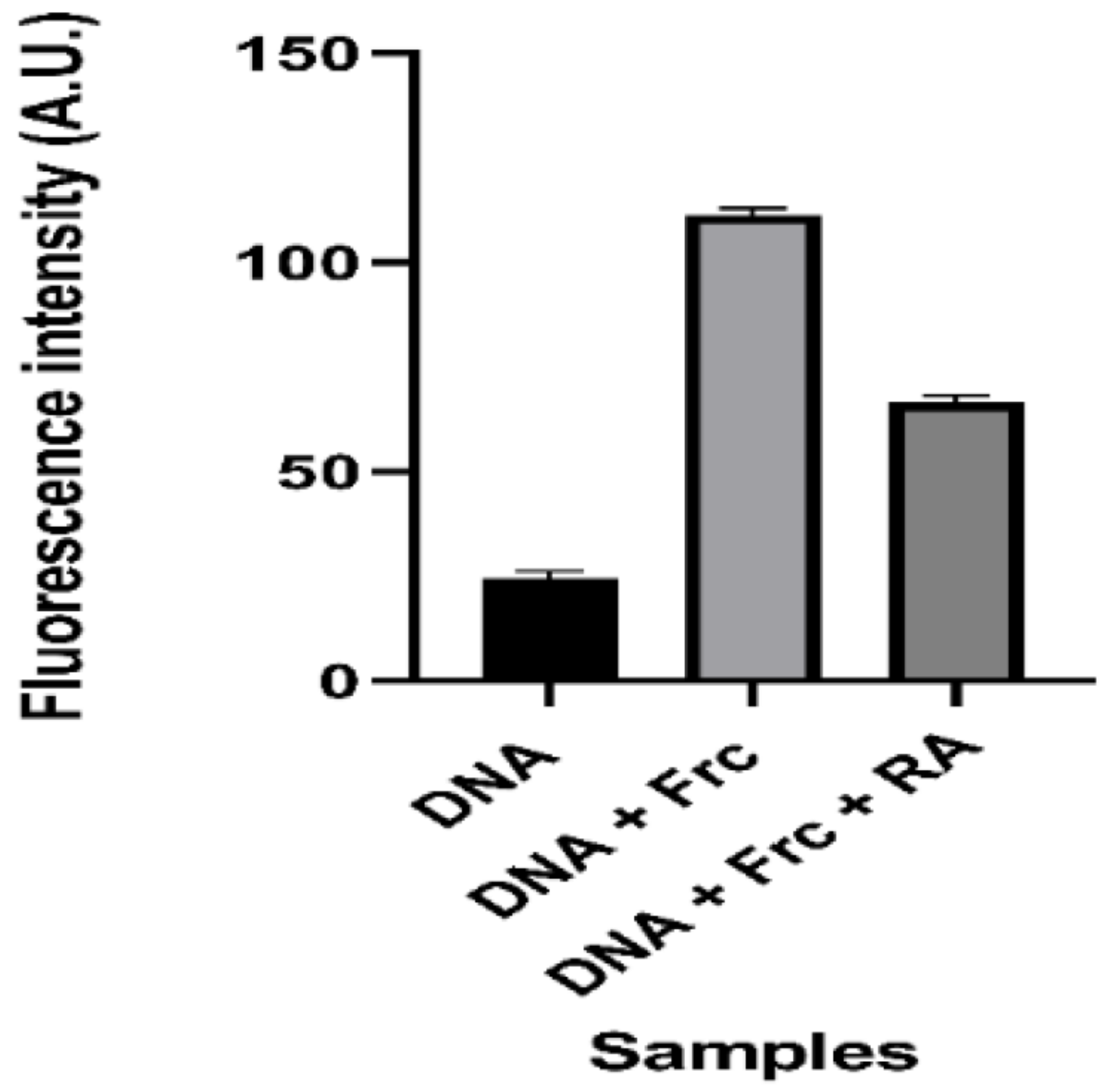

Figure 3

Fluorescence intensity of the native DNA, glycated (DNA + Fructose (Frc)) and treated with rosmarinic acid $(\mathrm{RA})$. The experiments were performed in triplicates. 
A) Native

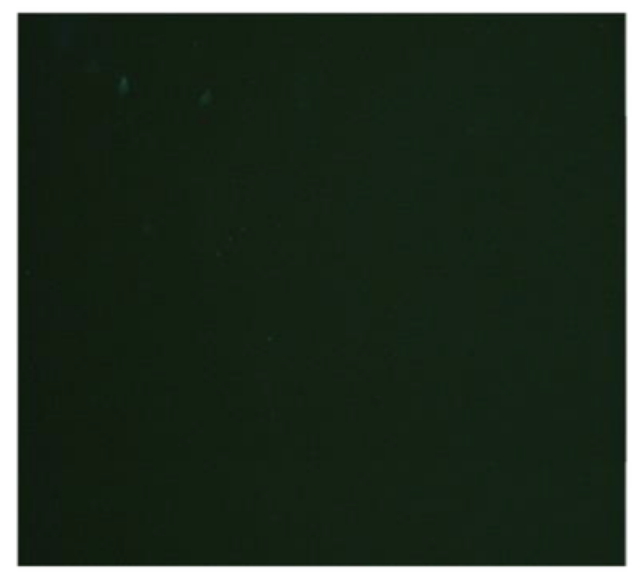

B) Glycated

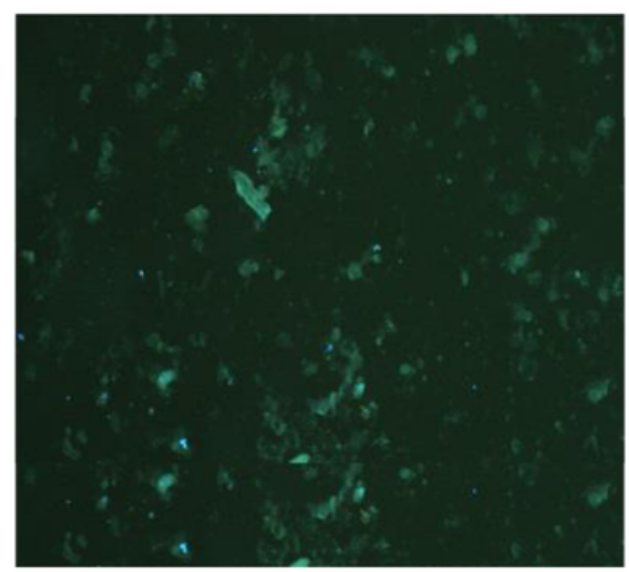

C) Treated with RA

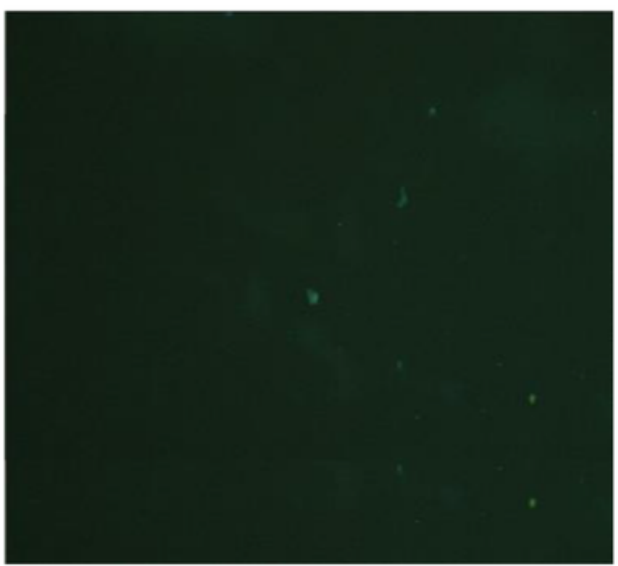

Figure 4

Fluorescence microscopic imaging, the native DNA (A), the glycated DNA (B), and the glycated DNA in the presence of $25 \mu \mathrm{M}$ RA (C).

A) Native

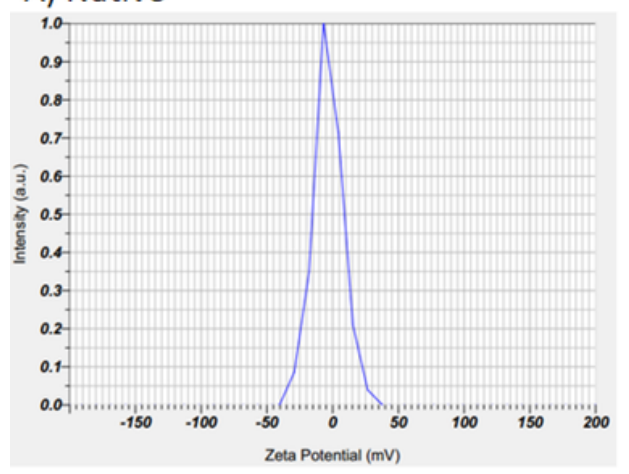

B) Glycated

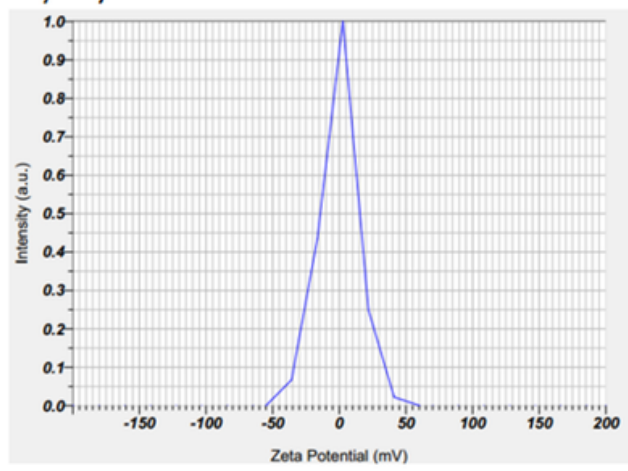

C) Treated with RA

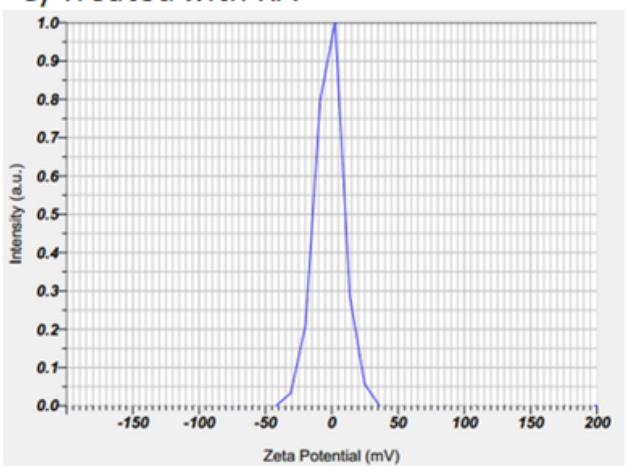

Figure 5

Zeta potential intensity distributions for the native DNA: zeta potential (mean) $=-3.5 \mathrm{mV}(\mathrm{A})$, the glycated DNA: $-0.5 \mathrm{mV}(\mathrm{B})$, and the glycated DNA with RA: -1.8 (C). 


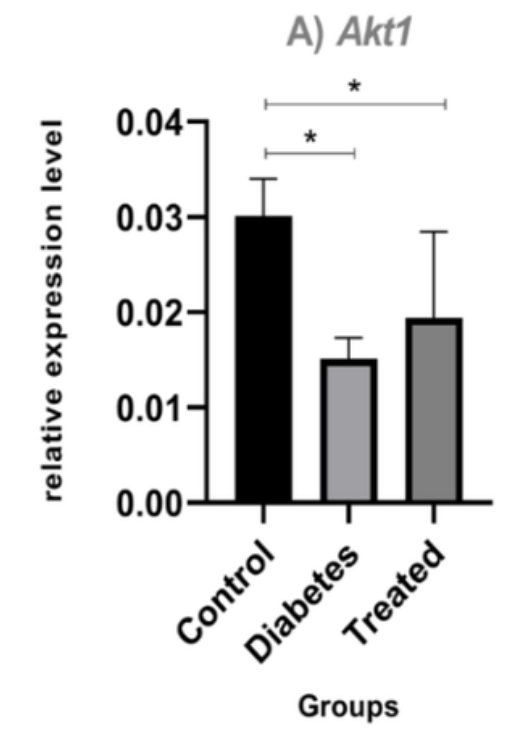

B) Akt2

C) Akt3
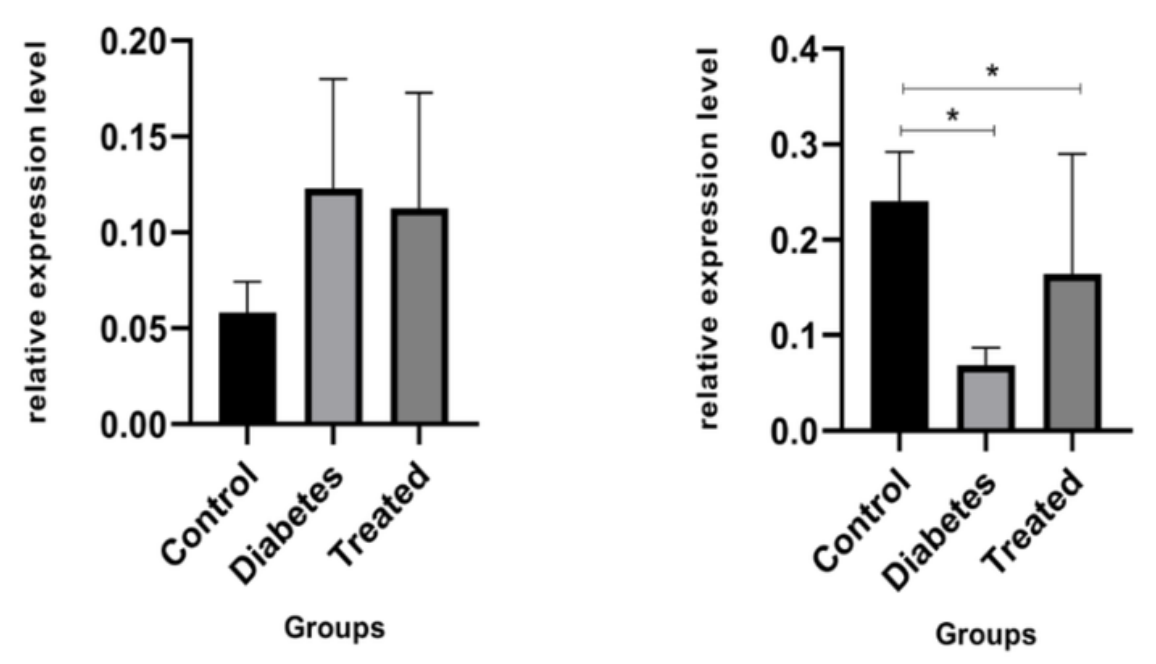

Figure 6

Relative expression of Akt genes in the hippocampus between control, diabetic and diabetic groups treated with RA, by real-time PCR. In the diabetic and treated groups, respectively, there was a significant down-regulation of $47 \%$ and $32 \%$ for Akt 1 compared to the control group. $\left({ }^{*} P<0.05\right)(A)$. Comparison of the relative expression of $A k t 3$, between the control group with the diabetic and treated groups showed a significant down-regulation of $67 \%$ and $20 \%$, respectively $\left({ }^{*} P<0.05\right)(B)$. There was, however, no significant difference in the Akt2 gene expression between the three groups $(P>0.05)(C)$. The columns represent the mean \pm SEM. 